\title{
Unprotected Sex with Injecting Drug Users among Iranian Female Sex Workers: Unhide HIV Risk Study
}

\author{
Khodabakhsh Ahmadi, ${ }^{1}$ Majid Rezazade, ${ }^{2}$ Mohammad Nafarie, ${ }^{3}$ Babak Moazen, ${ }^{4,5}$ Mosaieb \\ Yarmohmmadi Vasel, ${ }^{6}$ and Shervin Assari ${ }^{7}$
}

${ }^{1}$ Behavioral Sciences Research Center, Baqiyatallah University of Medical Sciences, Tehran 14548, Iran

${ }^{2}$ AIDS Prevention and Control Committee, Welfare Organization State, Tehran, Iran

${ }^{3}$ Welfare Organization State, Tehran, Iran

${ }^{4}$ Department of Health Behavior, Medicine and Health Promotion Institute, Tehran, Iran

${ }^{5}$ Universal Network for Health Information Dissemination and Exchange (UNHIDE), Tehran, Iran

${ }^{6}$ Department of Psychology, Bu-Ali Sina University, Hamedan, Iran

${ }^{7}$ Department of Health Behavior and Health Education, School of Public Health, University of Michigan, Ann Arbor, MI 48109, USA

Correspondence should be addressed to Khodabakhsh Ahmadi, khodabakhsh.ahmadi@gmail.com

Received 29 September 2011; Revised 18 December 2011; Accepted 9 January 2012

Academic Editor: Guido Poli

Copyright ( $\odot 2012$ Khodabakhsh Ahmadi et al. This is an open access article distributed under the Creative Commons Attribution License, which permits unrestricted use, distribution, and reproduction in any medium, provided the original work is properly cited.

\begin{abstract}
Purpose. To assess the prevalence and associated factors of unprotected sex with injecting drug users (IDUs) among a sample of female sex workers (FSWs) in Iran. Methods. This cross-sectional study included 144 FSWs who were interviewed as a part of Unhide HIV Risk Study, a national behavioral survey focusing on various high-risk populations, including IDUs, FSWs, and Men who have Sex with Men (MSMs) in 2009. The survey was conducted in eight provinces in Iran using respondent-driven sampling. Participants' sociodemographic status, HIV knowledge, and HIV attitude were analyzed via logistic regression to determine the predictors of unprotected sex with IDU(s) during the past month. Results. Nineteen percent of FSWs reported at least one occasion of unprotected sex with IDU(s) in the month preceding the study. Higher educational level $(\mathrm{OR}=-0.653,95 \% \mathrm{CI}=-1.192$ to $-0.115)$, perceived HIV risk $(\mathrm{OR}=-1.047,95 \% \mathrm{CI}=-2.076$ to -0.019 ), and perceived family intimacy during childhood $(\mathrm{OR}=-1.104,95 \% \mathrm{CI}=-1.957$ to -0.251$)$ were all independently associated with lower odds of having unprotected sex with IDU(s) in the month preceding the study. Age, marital status, living condition, HIV knowledge, and perceived behavioral control did not affect the odds of FSWs having sex with IDUs. Conclusion. Perceived HIV risk, which is a modifiable factor, seems to be a promising target for harm reduction interventions amongst Iranian female sex workers. Data presented here may aid in reducing or eliminating the role of sex workers as a bridge for HIV transmission from IDUs to the general population in Iran.
\end{abstract}

\section{Introduction}

Both its location amid a major regional narcotics transit route and the increasing drug injection rate have made Iran a country with a concentrated epidemic of $\operatorname{HIV}[1,2]$. Based on data from the Joint United Nations Program on HIV/AIDS (UNAIDS), a total of 92,000 (74,000-120,000) HIV positive people were living in Iran at the end of 2009 [3].

McFarland and colleagues have discussed the challenges associated with conducting research on HIV-related behaviors amongst at-risk groups, such as female sex workers
(FSWs) and men who have sex with men (MSMs) in Middle Eastern countries. They argue that this may be, in part, related to sociocultural sensitivities and political restrictions [4]. Whatever the cause of this difficulty is, the consequences do not change. Though numerous studies in this field have been conducted, our understanding about HIV risk behaviors in this particular region is very limited, and this limited knowledge hinders our ability to intervene.

Female sex workers are considered an epidemiologic "core group" for transmission sexually transmitted diseases (STDs), including HIV. This is partly attributable to both 
the high number and rapid turnover of sexual partners and its most common consequences, such as genital trauma, resulting from the reduction in lubricating vaginal fluid due to the use of incompetent astringents. The higher rate of STD transmission in this group is also attributable to several structural and environmental obstacles that prevent FSWs from receiving preventive interventions $[5,6]$. Although available data are generally limited in this area, especially in some developing countries $[7,8]$, high prevalence of STDs among FSWs has been reported [9].

One particular cause of STD transmission among FSWs is unprotected sexual relationships with injecting drug users (IDUs) [10], who serve as reservoirs for HIV, hepatitis C or B [11], in addition to their high-risk sexual [10] and injecting [12] behaviors. The considerable prevalence of HIV and HCV-estimated to be about $14 \%$ and $80 \%$, respectivelyamong Iranian IDUs at the end of 2009 [3] suggests the large role this population has in transmission of these infections to the general Iranian population.

Although anecdotal accounts often emphasize the role of IDUs and FSWs in HIV transmission, few empirical data exist on the predictors of unprotected sex between FSWs and IDUs-two major at-risk groups for HIV infection. The aim of this study was to determine the rate and associated factors of unprotected intercourse with IDU(s) among Iranian FSWs.

\section{Methods}

This cross-sectional study included 144 FSWs who were interviewed as a part of Unhide HIV-Risk Study, a national behavioral survey of different high-risk populations, including IDUs, FSWs, and Men who have Sex with Men (MSMs) in 2009.

2.1. Design and Setting. This cross-sectional study used data from Iranian noninjecting FSWs who participated in UNHIDE HIV-Risk Study. This was a national survey conducted in eight different provinces of Iran: Tehran, Fars, Isfahan, Markazi, Khuzestan, Guilan, Khorasan, and Azerbaijan. The survey of the unique population was conducted by the Behavioral Sciences Research Center at Baqiyatallah University of Medical Sciences during 2009.

The study was named Unhide HIV Risk, because it was aided by an international network, Universal Network for Health Information Dissemination and Exchange (UNHIDE), to explore different aspects of risk-taking among Iranian FSWs, IDUs, or MSMs. The ultimate goal of the study was to provide evidence needed for interventions and health promotion programs aimed at the population of interest. UNHIDE is an international network which tries to increase the availability of research-based knowledge in different disciplines of public health, which can be used for policy making and program planning.

2.2. Ethical Procedures. Informed consent was obtained from all participants after they had been verbally assured that the information would be kept confidential, especially from the correctional system; additionally, all checklists and questionnaires were anonymous. The Ethical Review Committee of the Baqiyatallah University of Medical Sciences approved the study.

2.3. Participants and Sampling. All participants were noninjecting FSWs recruited from streets in the above listed provinces. Participants were selected using snowball sampling over a 7-month period in 2009. Only participants who reported no injection during their lifetime were entered into this analysis.

\section{Interview Process}

Each interview lasted up to 60 minutes. No monetary incentive was offered to the participants. University-trained research assistants interviewed our participants; training for the interviewers was conducted through a series of workshops. All participants received HIV education and free condoms.

3.1. Measures. Our questionnaire measured sociodemographic data (age, gender, educational level, housing, and occupational situation), family data (marital status and perceived family intimacy during childhood), HIV knowledge (knowledge about safe and unsafe sex, as well as other HIV transmission routes), HIV attitude (perceived HIV risk, perceived need for HIV education, perceived behavior control, and intention), and HIV risk behaviors.

3.2. Main Outcome. The following single item measure was applied to determine unprotected sex with IDU(s): "During the past month, how many times did you have sex with a male drug injector who did not use a condom?" Sexual risk taking behaviors have been assessed by a single question in prior studies $[13,14]$.

3.3. Statistical Analysis. Data were processed in the Statistical Package for the Social Sciences 13 (SPSS Inc, IL, USA) for Windows. For bivariate analysis, Mann-Whitney $U$ and chi-square tests were applied. The logistic regression model was used to determine associated factors of unprotected sex among participants. Whereas none of the bivariates showed a significant association with the outcome, predictors which were supported by the literature were entered into the regression analysis. Odds ratios (ORs) and 95\% Confidence Intervals $(\mathrm{CI})$ are reported. Significance level was set at $P<0.05$.

\section{Results}

Of the 144 female sex workers included in this study, 51\% were married, $89 \%$ had at least a primary education, $35 \%$ were homemakers, and $21.5 \%$ reported living with friends. The data indicated that $32.6 \%$ of the FSWs reported themselves being exposed to much or too much violence by their family members; $35 \%$ reported no or little intimacy between their family members; $41.7 \%$ thought that they would never acquire HIV in their lifetime; $97 \%$ were eager to know about 
TABLE 1: Sociodemographic data among Iranian female sex workers who have sex with injecting drug users $(n=144)$.

\begin{tabular}{|c|c|c|}
\hline Data & Number & Percent \\
\hline \multicolumn{3}{|l|}{ Marital status } \\
\hline Single & 69 & 47.9 \\
\hline Married & 74 & 51.4 \\
\hline Missing & 1 & 0.7 \\
\hline \multicolumn{3}{|l|}{ Educational level } \\
\hline Uneducated & 13 & 9.0 \\
\hline Primary school & 19 & 13.2 \\
\hline Some secondary school & 67 & 46.3 \\
\hline High school diploma & 28 & 19.4 \\
\hline Associated degree & 9 & 6.3 \\
\hline Bachelor's degree and higher & 5 & 3.5 \\
\hline Missing & 3 & 2.1 \\
\hline \multicolumn{3}{|l|}{ Housing } \\
\hline Personal & 17 & 11.8 \\
\hline Rental & 77 & 54.2 \\
\hline Father's house & 37 & 25.7 \\
\hline Friend's house & 6 & 4.2 \\
\hline Relatives house & 5 & 3.5 \\
\hline Missing & 2 & 1.4 \\
\hline \multicolumn{3}{|l|}{ Occupational status } \\
\hline Student & 9 & 6.3 \\
\hline Self-employee & 11 & 7.6 \\
\hline Employee & 11 & 7.6 \\
\hline Homemaker & 51 & 35.4 \\
\hline Home service & 8 & 5.6 \\
\hline Work at private companies & 19 & 13.2 \\
\hline Unemployed & 24 & 16.7 \\
\hline Missing & 10 & 6.9 \\
\hline \multicolumn{3}{|l|}{ Living status } \\
\hline Alone & 11 & 7.6 \\
\hline With family members & 115 & 59 \\
\hline With others & 17 & 11.9 \\
\hline Missing & 1 & 0.7 \\
\hline
\end{tabular}

HIV and its transmission routes; $24 \%$ believed they had no HIV knowledge; 38\% expressed that radio and television were their main means of acquiring HIV knowledge; 53\% had never received face-to-face HIV education (Tables 1 and 2).

Twenty-seven Iranian female sex workers (19\%) reported having sex with IDU(s) during the past month. In the bivariate analysis, marital status was not associated with this outcome. Educational level $(P=0.513)$, family intimacy $(P=0.093)$, and perceived HIV risk $(P=0.774)$ did not show any significant difference between FSWs who reported sex with IDU(s) and those who did not. HIV knowledge was not significantly different between those with and those without unprotected sex with IDU(s) $(P=0.513)$.

In the logistic regression, higher educational level $(\mathrm{OR}=$ $-0.018,95 \% \mathrm{CI}=-1.192$ to -0.115$)$, perceived HIV risk $(\mathrm{OR}=-0.046,95 \% \mathrm{CI}=-2.076$ to -0.019$)$, and family intimacy during childhood $(\mathrm{OR}=-0.012,95 \% \mathrm{CI}=-1.957$ to -0.251 ) were associated with lower odds of unprotected sex with IDU(s) among Iranian noninjecting female sex workers (Table 3).
TABLe 2: Childhood trauma and HIV attitude among Iranian female sex workers who have sex with injecting drug users $(n=144)$.

\begin{tabular}{|c|c|c|}
\hline Childhood trauma & Number & Percent \\
\hline \multicolumn{3}{|l|}{ Exposure to violence by family members } \\
\hline Never & 25 & 17.4 \\
\hline Little & 31 & 21.5 \\
\hline Sometimes & 37 & 25.7 \\
\hline Much & 34 & 23.6 \\
\hline Too much & 13 & 9 \\
\hline Missing & 4 & 2.8 \\
\hline \multicolumn{3}{|l|}{ Family intimacy } \\
\hline Not at all & 14 & 9.7 \\
\hline A little & 35 & 24.3 \\
\hline Some & 52 & 36.1 \\
\hline High & 29 & 20.1 \\
\hline Very high & 11 & 7.6 \\
\hline Missing & 3 & 2.1 \\
\hline \multicolumn{3}{|l|}{ HIV attitude } \\
\hline \multicolumn{3}{|l|}{ Perceived HIV risk } \\
\hline Not at all & 60 & 41.7 \\
\hline A little & 38 & 26.4 \\
\hline Some & 35 & 24.3 \\
\hline High & 7 & 4.9 \\
\hline Very high & 3 & 2.1 \\
\hline Missing & 1 & 0.7 \\
\hline \multicolumn{3}{|l|}{ Perceived need for HIV knowledge } \\
\hline Not at all & 4 & 2.8 \\
\hline A little & 11 & 7.6 \\
\hline Some & 33 & 22.9 \\
\hline High & 45 & 31.3 \\
\hline Very high & 51 & 35.4 \\
\hline \multicolumn{3}{|l|}{ Perceived HIV knowledge } \\
\hline Not at all & 34 & 23.6 \\
\hline A little & 31 & 21.5 \\
\hline Some & 39 & 27.1 \\
\hline High & 33 & 22.9 \\
\hline Very high & 5 & 3.5 \\
\hline Missing & 2 & 1.4 \\
\hline \multicolumn{3}{|l|}{ Source of HIV Information } \\
\hline Radio and television & 29 & 20.1 \\
\hline Newspaper & 7 & 4.9 \\
\hline Books & 5 & 3.5 \\
\hline Friends & 21 & 14.6 \\
\hline Educational programs/interventions & 14 & 9.7 \\
\hline Some mixing ways & 46 & 31.9 \\
\hline Missing & 22 & 15.3 \\
\hline \multicolumn{3}{|l|}{ Participation in HIV education programs } \\
\hline Never & 77 & 53.5 \\
\hline Once & 15 & 10.4 \\
\hline Twice & 11 & 7.6 \\
\hline More & 37 & 25.7 \\
\hline Missing & 4 & 2.8 \\
\hline
\end{tabular}

\section{Discussion}

About 20\% of Iranian noninjecting FSWs reported having sex with at least one IDU during past month. Our findings suggest that a lower tendency toward unprotected sex with 
TABle 3: Predictors of unprotected sex with injecting drug users among Iranian female sex workers $(n=144)$.

\begin{tabular}{lccc}
\hline \multirow{2}{*}{ Characteristic } & \multirow{3}{c}{ OR } & Lower & Upper \\
\hline Higher educational level & -0.653 & -1.192 & -0.115 \\
$\begin{array}{l}\text { Higher family intimacy during } \\
\text { childhood }\end{array}$ & -1.104 & -1.957 & -0.251 \\
Perceived HIV risk & -1.047 & -2.076 & -0.019 \\
\hline
\end{tabular}

an IDU amongst sex workers with higher educational levels increased perceived HIV risk and family intimacy among childhood. HIV knowledge, however, failed to be predictive of sex with IDUs in our study. These findings shed more light on a previously understudied outcome-unprotected sex with IDUs committed by noninjecting Iranian FSWs

Having a higher educational level $(\mathrm{OR}=-0.018)$ was shown to be associated with unprotected sex with IDUs among Iranian FSWs. Although most of studies have shown an association between educational level and risky behaviors [13-15], there are studies that have reported a lack of association [16]. Based on the Strain Theory, delinquencies may occur among those who get frustrated by the inability to succeed in school [17]. The Social Control Theory also suggests that this association results from the protective effect of institutions on instilling social norms and sanctioning deviance [17]. The Primary Socialization Theory suggests that weak school bonds may increase the amount of time spent with deviant peers [18]. All these theories can be used to explain an association between education level and risktaking. In addition, it is possible that those with lower education may overreport behavior problems, while those with higher education may underreport behavior problems [19].

Higher perceived HIV risk $(\mathrm{OR}=-0.046)$ was another protective factor against unprotected sex with IDU(s). Most, $[20,21]$ but not all, [22] studies support our findings, and this inconsistency might be explained by measurement incompatibility, subpopulation and behavioral differences, and unexamined critical factors constructing perceived risk [22] across studies. Perceived risk is a construct of the Health Belief Model (HBM), which has been widely used for HIV prevention interventions. The Health Belief Model has been utilized over time by many authors to explain high-risk sexual behaviors among commercial sex workers previously. In a study conducted on 211 male street prostitutes, between the ages of 18 and 51 in the USA, perceived HIV risk was not significantly associated with their high-risk behaviors [23]. Other studies have shown that perceived susceptibility to HIV and perceived benefits of condom use may reduce HIV risk-taking [23]. Additionally, in another study, perceived susceptibility to STDs was a predictor of condom use among FSWs in Indonesia [24].

As reported by the United Nations, the Health Belief Model is one of the models that can be used as a basis for prevention of HIV via sexual behaviors [25]. Perceived HIV risk is a complex construct because female sex workers may be seen as at risk, not because of their current behavior, but because of their past behaviors or because of their partner [25].

More family intimacy during childhood may protect FSWs from unprotected sex with IDUs $(\mathrm{OR}=-0.012)$. Several studies have shown negative impact of childhood violence, physical abuse [26-28], and even witnessing family violence on future engagement in high-risk behaviors [29]. The protective role of family connectedness against deviances has been widely acknowledged [30]. As it has been suggested before, strengthening family ties and family involvement may have a protective effect on sexual risk taking of girls [31].

Low efficacy of programs that only promote HIV knowledge in relation to risky behaviors has been previously reported [32]. Program planners may consider focusing on perceived HIV risk to reduce instances of unprotected sex amongst Iranian female sex workers with IDU(s). Although this study only measured individual level data, proper prevention interventions should consider interpersonal, environmental, and structural context in which sexual behaviors occur, as well [33].

Some researchers have argued that the ultimate target for any program for FSWs should be their empowerment to quit prostitution [6]. Sex work is different in different settings [34], and such diversities should be considered when a program is designed or implemented [25].

Because of its cross-sectional design, our study is not conclusive about causal relations. The considerable amount of missing data was another limitation in this study. As the data were collected via self-report, overreporting and/or underreporting are possible consequences [35]. Small sample size and the use of respondent-driven sampling may also have limited our study. In addition, we did not collect data regarding whether the IDU is a regular or temporary client of the sex worker. This study also has not measured the context in which sex has taken place. Finally, a portion of FSWs who did not reported sex with IDUs may likely be unaware of their sexual partner's injection behavior. However, due to cultural, political, and religious circumstances, few studies have been done on Iranian FSWs [36]. Therefore, even with the aforementioned limitations, this study sheds light on risk-taking behavior of FSWs, and it may help harm reduction practice in Iran.

In conclusion, public health officials should not assume that providing educational information about HIV transmission would lead to behavioral change among sex workers. We instead suggest theory-based interventions, with perception of risk as the integral component to reducing risky behaviors and increasing condom use among Iranian female sex works.

\section{Acknowledgments}

Unhide HIV Risk Study was a national survey of risky behaviors in high-risk populations in Iran. The paper was financially supported by Global Fund to Fight AIDS, Tuberculosis and Malaria (GFATM), and United Nations Development Program (UNDP). The study was conducted under signed Memorandums of Understanding between UNDP, Center for Disease Control (CDC) of Iranian Ministry of 
Health and Medical Education (MOHME), Welfare Organization (WO), Behavioral Sciences Research Center (BSRC), Medicine and Health Promotion Institute (MHPI), and Universal Network for Health Information Dissemination and Exchange (UNHIDE). The BSRC and WO have designed the study, developed the questionnaire, and collected the data. MHPI and UNHIDE have conducted literature review, analyzed data, and completed paper writing. The authors have substantial contributions to different parts of the work, and all have approved the final draft of the paper. The authors would like to thank Ashley Heilingoetter, MPH, University of Michigan, for language edit of the final version of this manuscript.

\section{References}

[1] A. Mohammadpour, Z. P. Yekta, A. R. Nikbakht Nasrabadi, and M. Mohraz, "Coming to terms with a diagnosis of HIV in Iran: a phenomenological study," Journal of the Association of Nurses in AIDS Care, vol. 20, no. 4, pp. 249-259, 2009.

[2] A. Rahimi-Movaghar, E. M. Razaghi, E. Sahimi-Izadian, and M. Amin-Esmaeili, "HIV, hepatitis C virus, and hepatitis B virus co-infections among injecting drug users in Tehran, Iran," International Journal of Infectious Diseases, vol. 14, no. 1, pp. e28-e33, 2010.

[3] UNAIDS. Report on the global AIDS epidemic, 2010, http:// unaids.org/globalreport/documents/20101123_GlobalReport_ full_en.pdf.

[4] W. McFarland, L. J. Abu-Raddad, Z. Mahfoud et al., "HIV/AIDS in the middle east and North Africa: new study methods, results, and implications for prevention and care," AIDS, vol. 24, no. 2, supplement, pp. S1-S4, 2010.

[5] B. Vuylsteke, A. Das, G. Dallabetta, and M. Laga, "Preventing HIV among sex workers," in HIV Prevention; A Comprehensive Approach, K. H. Mayer and H. F. Pizer, Eds., pp. 376-406, Elsevier, California, Calif, USA, 2009.

[6] M. L. Rekart, "Sex-work harm reduction," The Lancet, vol. 366, no. 9503, pp. 2123-2134, 2005.

[7] World Health Organization, "HIV and sexually transmitted infection prevention among sex workers in Eastern Europe and Central Asia," 2006, http://www.whqlibdoc.who.int/unaids/2006/9291734942_eng.pdf.

[8] C. L. Szwarcwald, F. I. Bastos, N. Gravato, R. Lacerda, P. N. Chequer, and E. A. De Castilho, "The relationship of illicit drug use to HIV-infection among commercial sex workers in the city of Santos, São Paulo, Brazil," International Journal of Drug Policy, vol. 9, no. 6, pp. 427-436, 1998.

[9] R. Steen and G. Dallabetta, "Sexually transmitted infection control with sex workers: regular screening and presumptive treatment augment efforts to reduce risk and vulnerability," Reproductive Health Matters, vol. 11, no. 22, pp. 74-90, 2003.

[10] M. Y. Iguchi, D. A. Bux Jr., H. Kushner, and V. Lidz, "Correlates of HIV risk among female sex partners of injecting drug users in a high-seroprevalence area," Evaluation and Program Planning, vol. 24, no. 2, pp. 175-185, 2001.

[11] S. A. Strathdee, M. M. Philbin, S. J. Semple et al., "Correlates of injection drug use among female sex workers in two MexicoU.S. border cities," Drug and Alcohol Dependence, vol. 92, no. 1-3, pp. 132-140, 2008.

[12] V. A. Gyarmathy and A. Neaigus, "The relationship of sexual dyad and personal network characteristics and individual at- tributes to unprotected sex among young injecting drug users," AIDS and Behavior, vol. 13, no. 2, pp. 196-206, 2009.

[13] H. Yang, X. Li, B. Stanton et al., "Condom use among female sex workers in China: role of gatekeepers," Sexually Transmitted Diseases, vol. 32, no. 9, pp. 572-580, 2005.

[14] M. C. Zea, C. A. Reisen, P. J. Poppen, and F. T. Bianchi, "Unprotected anal intercourse among immigrant Latino MSM: the role of characteristics of the person and the sexual encounter," AIDS and Behavior, vol. 13, no. 4, pp. 700-715, 2009.

[15] K. E. Fothergill, M. E. Ensminger, K. M. Green, R. M. Crum, J. Robertson, and H. S. Juon, "The impact of early school behavior and educational achievement on adult drug use disorders: a prospective study," Drug and Alcohol Dependence, vol. 92, no. 1-3, pp. 191-199, 2008.

[16] E. R. Oetting and J. F. Donnermeyer, "Primary socialization theory: the etiology of drug use and deviance. I," Substance Use and Misuse, vol. 33, no. 4, pp. 995-1026, 1998.

[17] J. A. Kam, M. J. Cleveland, and M. L. Hecht, "Applying General Strain Theory to Examine Perceived Discrimination's Indirect Relation to Mexican-Heritage Youth's Alcohol, Cigarette, and Marijuana Use," Prevention Science, vol. 11, no. 4, pp. 397-410, 2010.

[18] E. R. Oetting and J. F. Donnermeyer, "Primary socialization theory: the etiology of drug use and deviance. I," Substance Use and Misuse, vol. 33, no. 4, pp. 995-1026, 1998.

[19] N. D. Brener, J. O. Billy, and W. R. Grady, "Assessment of factors affecting the validity of self-reported health-risk behavior among adolescents: evidence from the scientific literature," Journal of Adolescent Health, vol. 33, no. 6, pp. 436-457, 2003.

[20] I. M. Joung, A. E. Kunst, E. van Imhoff, and J. P. Mackenbach, "Education, aging, and health: to what extent can the rise in educational level relieve the future health (care) burden associated with population aging in the Netherlands?" Journal of Clinical Epidemiology, vol. 53, no. 9, pp. 955-963, 2000.

[21] L. Koivusilta, R. Arja, and V. Andres, "Health behaviours and health in adolescence as predictors of educational level in adulthood: a follow-up study from Finland," Social Science and Medicine, vol. 57, no. 4, pp. 577-593, 2003.

[22] C. A. Vereecken, L. Maes, and D. De Bacquer, "The influence of parental occupation and the pupils' educational level on lifestyle behaviors among adolescents in Belgium," Journal of Adolescent Health, vol. 34, no. 4, pp. 330-338, 2004.

[23] P. M. Simon, E. V. Morse, P. M. Balson, H. J. Osofsky, and H. R. Gaumer, "Barriers to human immunodeficiency virus related risk reduction among male street prostitutes," Health Education Quarterly, vol. 20, no. 2, pp. 261-273, 1993.

[24] L. Thorpe, K. Ford, P. Fajans, and D. N. Wirawan, "Correlates of condom use among female prostitutes and tourist clients in Bali, Indonesia,” AIDS Care, vol. 9, no. 2, pp. 181-197, 1997.

[25] UNAIDS, "Sexual behavioral change for HIV: where have all the theories taken us?" 1999, http://www.who.int/hiv/strategic/surveillance/en/unaids_99_27.pdf.

[26] L. E. Wagenknecht, L. L. Perkins, G. R. Cutter et al., "Cigarette smoking behavior is strongly related to educational status: the CARDIA study," Preventive Medicine, vol. 19, no. 2, pp. 158$169,1990$.

[27] H. McKenna, P. Slater, T. McCance, B. Bunting, A. Spiers, and G. McElwee, "The role of stress, peer influence and education levels on the smoking behaviour of nurses," International Journal of Nursing Studies, vol. 40, no. 4, pp. 359-366, 2003.

[28] S. L. Bailey, L. J. Ouellet, M. E. Mackesy-Amiti et al., "Perceived risk, peer influences, and injection partner type predict 
receptive syringe sharing among young adult injection drug users in five U.S. cities," Drug and Alcohol Dependence, vol. 91, supplement 1, pp. S18-S29, 2007.

[29] C. L. Ford, M. Daniel, and W. C. Miller, "High rates of HIV testing despite low perceived HIV risk among AfricanAmerican sexually transmitted disease patients," Journal of the National Medical Association, vol. 98, no. 6, pp. 841-844, 2006.

[30] E. G. Ward, W. B. Disch, J. J. Schensul, and J. A. Levy, "Understanding low-income, minority older adult self-perceptions of HIV risk," The Journal of the Association of Nurses in AIDS Care, vol. 22, no. 1, pp. 26-37, 2011.

[31] S. A. Strathdee, D. M. Patrick, C. P. Archibald et al., "Social determinants predict needle-sharing behaviour among injection drug users in Vancouver, Canada," Addiction, vol. 92, no. 10, pp. 1339-1347, 1997.

[32] S. E. Evans, C. Davies, and D. DiLillo, "Exposure to domestic violence: a meta-analysis of child and adolescent outcomes," Aggression and Violent Behavior, vol. 13, no. 2, pp. 131-140, 2008.

[33] M. Sweat and J. Denison, "Reducing HIV incidence in developing countries with structural and environmental interventions," AIDS, vol. 9, pp. S251-257, 1995.

[34] K. Ford, D. Wirawan, and P. Fajans, "Factors related to condom. Use among four groups of female sex workers in Bali, Indonesia," AIDS Education and Prevention, vol. 10, no. 1, pp. 34-45, 1998.

[35] L. M. Niccolai, T. S. Kershaw, J. B. Lewis, D. V. Cicchetti, K. A. Ethier, and J. R. Ickovics, "Data collection for sexually transmitted disease diagnoses: a comparison of self-report, medical record reviews, and state health department reports," Annals of Epidemiology, vol. 15, no. 3, pp. 236-242, 2005.

[36] M. Jahani, S. Alavian, H. Shirzad, A. Kabir, and B. Hajarizadeh, "Distribution and risk factors of hepatitis B, hepatitis C, and HIV infection in a female population with "illegal social behaviour"'” Sexually Transmitted Infections, vol. 81, no. 2, p. 185, 2005. 


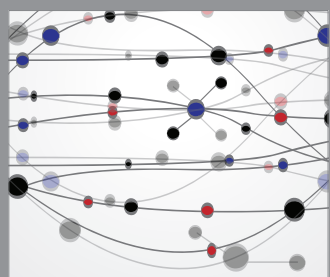

The Scientific World Journal
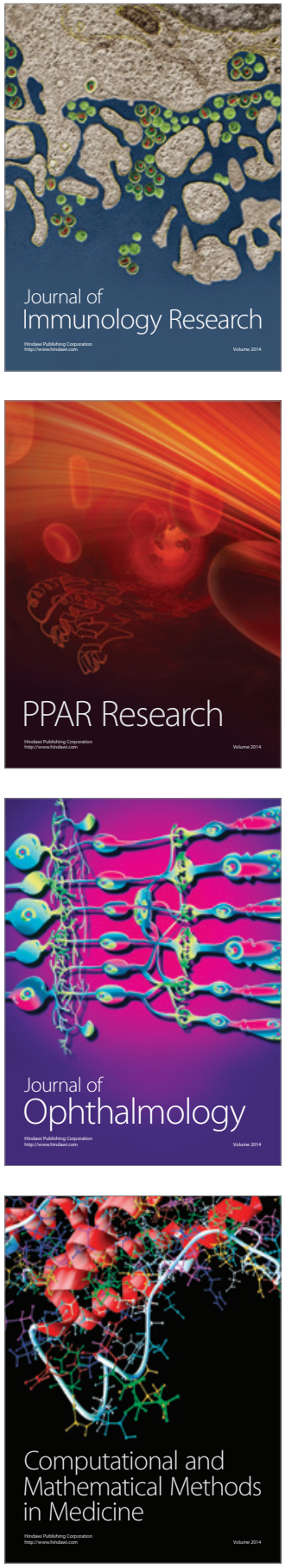

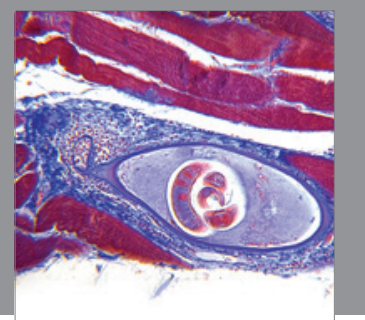

Gastroenterology

Research and Practice
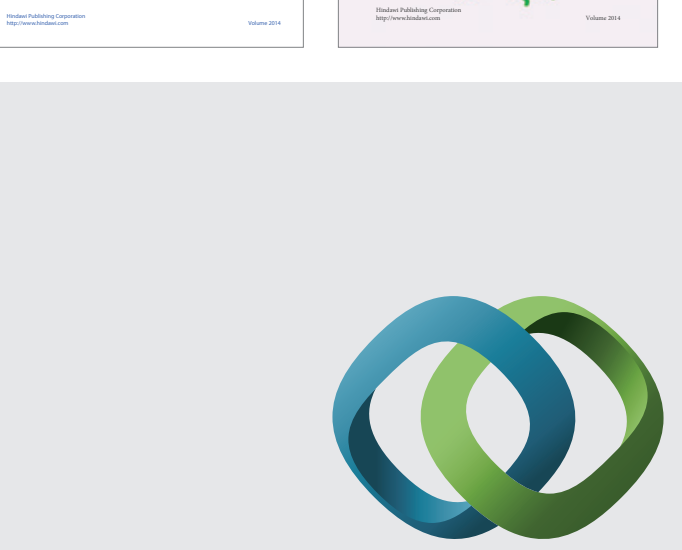

\section{Hindawi}

Submit your manuscripts at

http://www.hindawi.com
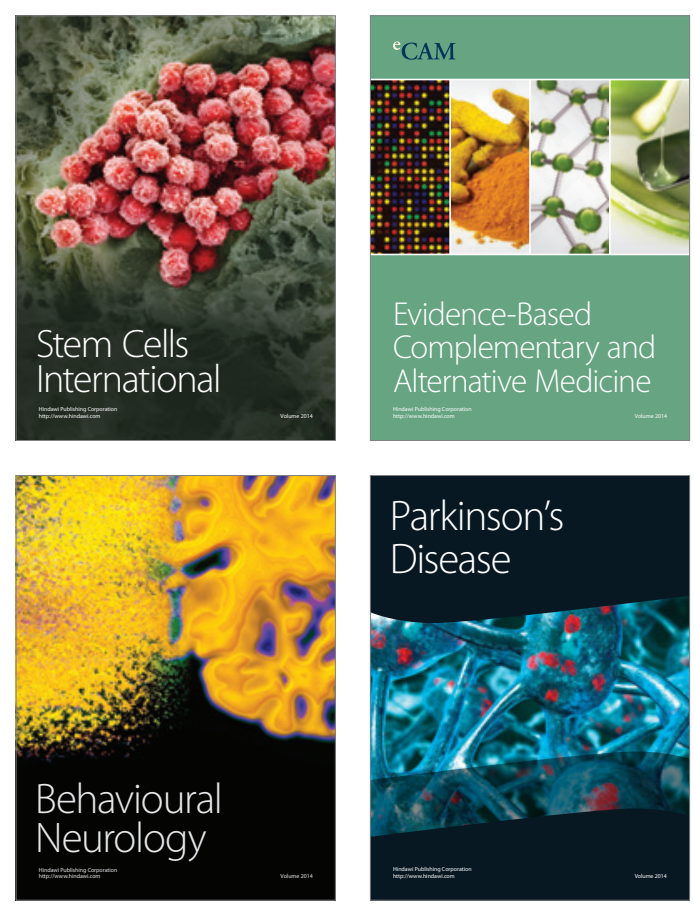

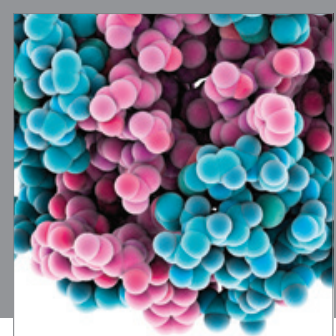

Journal of
Diabetes Research

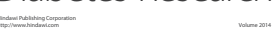

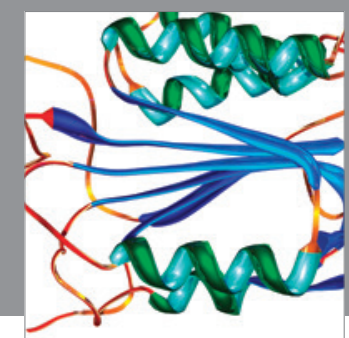

Disease Markers
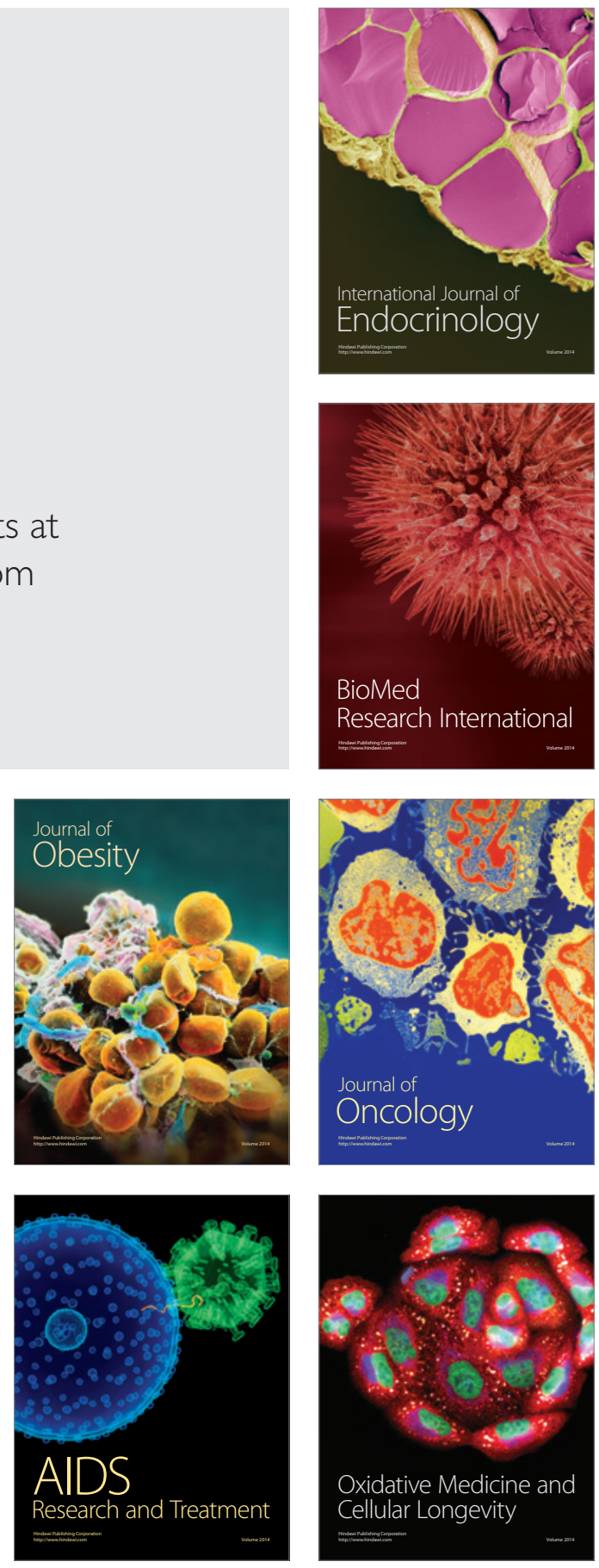